\title{
2
}

\section{Dilemmas in Social Media: A Categorization}

\begin{abstract}
This chapter presents five categories of ethical dilemmas that can arise for practitioners who are responsible for social media accounts in organizations. Executive students at a European business school have provided input to the categorization. The five categories to emerge from the material are the following: role dilemmas address how the agent in social media can have multiple roles, creating confusion about ethical responsibilities; tempo dilemmas occur because the exchanges in social media happen quickly, with a high risk of making mistakes; integrity dilemmas happen when the agent is tempted or pressured to act against personal and common values and principles; speech dilemmas are situations at the threshold of what one can reasonably and adequately post through a social medium; and competence dilemmas arise when the social media experts can exploit competence gaps in their own favor, with little risk of detection.
\end{abstract}

Keywords Social media $\bullet$ Role dilemmas $\bullet$ Speech dilemmas $\bullet$ Tempo dilemmas $\bullet$ Integrity dilemmas $\bullet$ Competence dilemmas 
This study aims to categorize ethical dilemmas encountered by employees who run the social media accounts in their organizations. These dilemmas can occur across disciplines, industries and professions. Input comes from executive students at a European business school, who, in their professional capacities, are responsible for handling Facebook, Twitter, LinkedIn, Instagram and other social media accounts on behalf of their employers. They have handed in memos describing concrete dilemmas from their everyday work. Over a five-year period, five sets of students have shared their experiences of facing situations where they have to decide between conflicting ethical considerations.

The most striking realization from initial readings of the first set of dilemma memos was that these executive students found themselves in the middle of complex and demanding ethical challenges in their daily work. It was not difficult for them to come up with vivid examples from their own work experience. They were neither outsiders nor observers of organizational ethics in action, but rather actors who regularly faced tough decisions for which there were more or less equally good ethical reasons for opposite alternatives.

A pattern that emerged in the opening stages was that of conflicting interpretations of what it means to be an active social media user. The professionals handling the social media accounts in their organizations expressed doubt and confusion regarding their own role and those of colleagues and leaders who also used different kinds of social media. It also appeared that the executive students had encountered challenges to their moral convictions and personal values. Several of them had encountered pressure to engage in activities that created moral dissonance (Kvalnes, 2019), a discrepancy between their personal moral standards and what they were expected or ordered to do. There was also substantial documentation of ethical concerns about the threshold for speaking one's mind, when colleagues and leaders were involved in harsh exchanges about controversial political and social issues.

Five categories of ethical dilemmas emerged from the research process of (1) interpreting written input from executive students, (2) discussing their examples in the classroom, (3) returning with suggested categories to the informants and (4) rewriting and modifying the categories (Table 2.1): 
Table 2.1 Categories of dilemmas

\begin{tabular}{|c|c|}
\hline Role dilemmas & $\begin{array}{l}\text { Who is the agent in social media? Professional, employee, } \\
\text { friend, owner, politician, private individual or more than one } \\
\text { of these at the same time? }\end{array}$ \\
\hline $\begin{array}{l}\text { Tempo } \\
\text { dilemmas }\end{array}$ & $\begin{array}{l}\text { What kind of information and opinions do we spread with the } \\
\text { touch of a finger? What do we miss out on if we slow down } \\
\text { and are more thoughtful? }\end{array}$ \\
\hline $\begin{array}{l}\text { Integrity } \\
\text { dilemmas }\end{array}$ & $\begin{array}{l}\text { To what extent should we downplay our own principles and } \\
\text { values to gain or keep friends, followers and clients and get } \\
\text { more likes? }\end{array}$ \\
\hline $\begin{array}{l}\text { Speech } \\
\text { dilemmas }\end{array}$ & $\begin{array}{l}\text { What kinds of opinions is it acceptable to express in social } \\
\text { media? Where do we draw the line of free speech in the } \\
\text { processes of expressing disagreement and defending } \\
\text { ourselves against what we perceive to be unreasonable } \\
\text { criticism? }\end{array}$ \\
\hline $\begin{array}{l}\text { Competence } \\
\text { dilemmas }\end{array}$ & $\begin{array}{l}\text { To what extent is it acceptable for professionals to exploit the } \\
\text { gaps in social media competence in their own favor? }\end{array}$ \\
\hline
\end{tabular}

This chapter presents each of these dilemma categories in further detail, with examples from the student memos. It concludes with an outline of how the five categories overlap and how one particular dilemma can contain elements that connect it to several-and even to all five-categories.

\section{$1 \quad$ Role Dilemmas}

Four of my colleagues have recently quit their jobs, and started working for a competing organization. Naturally, they remain in contact with former colleagues here, and have established friendships on Facebook, a platform that is an important arena for both organizations. Now I notice that my present colleagues share and like job-related content from those excolleagues, and thus help their company to spread information about their products. I think this is unacceptable, since they are assisting a competitor and undermining our own efforts to reach out to customers and become their preferred supplier of financial services.

Role dilemmas occur when the role of the person who is active in social media is unclear or open to different and conflicting interpretations. Are 
these words the expressions of a professional or a private person, a colleague or a friend, a company owner or a concerned citizen, an expert or a nonexpert, or a teacher or a dismayed employee? Dilemmas typically arise when the agent has one understanding of his or her role, whereas various others interpret the role differently, leading them to have conflicting ideas about what the appropriate response is.

A manager in a financial institution provided the above example. He was frustrated that his colleagues were more loyal to their friends and former colleagues than to their own organization. Their behavior suggested that they saw their role as friends as more important than their role as employees. The response this contributor received from his colleagues was that we live in an era for knowledge sharing. Social media like Facebook, LinkedIn and Twitter are designed to make information available to everybody. Knowledge hiding, where we try to gain advantages by guarding our own knowledge, is a thing of the past. It can be argued that sharing is good for the financial industry. Decision-makers must be alert and ready to develop new services and products based on insights that are available to everybody. The kind of knowledge sharing that this employee finds unacceptable actually triggers innovation and can be beneficial to all. This is an argument that can find support in research (Leonardi, 2017).

The student's reply to his colleagues was that even in a time of knowledge sharing, employees must show loyalty to their employer, particularly in situations where there is hard competition, and customer movement from one supplier to another can lead to deep economic problems for the one who is losing market shares. The role of being an employee should take priority over the role of being a friend and supporter.

Here is another example of a dilemma where decision-making becomes challenging due to confusion or uncertainty about the role, identity and position of the agent:

One of my colleagues is responsible for our interactions with business clients, and is the outward face people associate with our unit, even on various social media platforms. However, this year she has been a participant on a popular reality show. For the younger generation, this is exciting, but I believe that our more conservative and established clients are skeptical. When the contact is through social media, people tend to be more 
interested in her as a person, than in us as a company. Should she stay on in her role as head of business client relations?

In this case, the management may be reluctant to remove the employee from her position, since she generates public interest for the company, although they realize that the attention has nothing to do with her business role, and everything to do with her role in the reality show.

One student illustrated the blurred line between the agent as a professional and the agent as an engaged and enthusiastic private person:

I am employed in an internet shop for sports equipment. It is a perfect job for me, since I am enthusiastic about the range of products in this field, and regularly use them in my private life. Can I like, comment, and share my recommendations on Facebook and other platforms as a private citizen, without informing about my professional connection to the shop?

The informant in this case sees himself as a person with high moral standards, who would only make recommendations based on his actual experiences and beliefs about the product. By being open in social media about his role in the shop, he feared that people would unreasonably start to doubt his sincerity.

Discussions in the classroom confirmed that the above are examples of a kind of ethically charged situation that a professional who is responsible for the handling of social media accounts can encounter. From the agent's point of view, the dilemmas can occur in advance of a particular interaction. How will the message I am about to publish be interpreted? Am I entitled to express it? Based on one interpretation of my role, I should not post the message, but based on another, I am in my full right to do so. Will the recipients of the message understand that I make this claim as a private citizen and not as an employee of this particular organization?

One kind of role dilemma occurs when employees use social media to go beyond their designated roles at work, to be of service to customers, or defend the organization against criticism. In their social media interactions, they may be perceived as representatives of the organizations, even though they are operating from their personal social media accounts: 
I work for a railway company. We are eager to provide excellent customer service, and want to take care of the people who choose to travel with us. The service mentality is very important, and encouraged among the employees on the trains, and in the central office. However, we are not present in social media around the clock, so cannot provide immediate answers to social media inquiries about our services. The dilemma is that other employees-conductors, train drivers, technicians-who do not have access to the company's Facebook page respond to questions from travelers and the public from their personal Facebook pages. It is not part of their job description to do so, but they want to be of service and feel qualified to provide answers. The customers can mistakenly think that they are in dialogue with our official inquiry service. Some of these employees also defend the company against criticism that appear on Twitter and other social media, and may use arguments that are not in line with company policy. I encounter dilemmas where I have to respond to the eager activities of well-meaning colleagues, without causing offense to them. How do I outline the scope of action for such social media activities?

This social media administrator needs to tread carefully in addressing the situation with these colleagues. Their activities may also point to constructive alternative ways of organizing social media interaction in an organization. The voices of the people who work on the trains are authentic and real and may resonate better with the travelers than the voices of employees in central office. As is the case in other organizational contexts, delegating responsibility for social media activities to those who are closest to the core activities may stimulate a richer interaction with key stakeholders. Doing so also raises the risk of controversy and conflict, since the different individual voices may not be attuned to a common set of principles and ideas.

The input from the students indicates that role dilemmas can occur in the aftermath of an interaction. In hindsight, the agent may realize there can be more than one reasonable interpretation of a particular message or interaction, based on different understandings of his or her role. Then the choice can be made between remaining committed to the message and the way it was published and admitting that it was a mistake to express it in those terms. The sports enthusiast who also happens to work for a company that sells sports equipment may gradually realize that people 
have good reasons to doubt his honesty when he posts positive messages about products that can be bought from his employer.

Role dilemmas can also emerge in the context of negotiating the relationship between the person responsible for a social media account and that person's leaders or manager. Several of the informants point to their superiors' limited understanding of social media as a source of role dilemmas. When an employee has misbehaved on Facebook, some leaders delegate the responsibility to address the issue with the employee to the person who runs the Facebook account for the organization, rather than doing it themselves. When a train driver takes to Twitter to defend the organization, using sharper language than top management is comfortable with, it may fall to the person who runs the social media platforms to address the issue with the train driver. The social media professional may on the other hand think that it is the leader's responsibility to talk to the employee about it. Expertise in the field of social media is not a competence that renders a person qualified to tell an employee that he or she has overstepped an ethical line. Instead, that seems to be a responsibility tied to the role of being a leader. The final chapter of this book is dedicated to further discussion of social media ethics and leadership.

\section{Tempo Dilemmas}

Speed and timing emerged as another recurring feature in the input from the students. Several of them reflected on how participation in the hightempo exchanges on social media can become compulsive and put colleagues and friends in a position where they search for constructive ways to intervene:

I have an impulsive colleague who uses social media to immediately express his frustrations whenever we receive new guidelines and routines. People see him as a grumpy and angry person, who overreacts to the changes. We try to talk him out of expressing himself like this, but he has grown fond of the high tempo and immediate responses he gets in social media. What more can we, his colleagues, do? 
There is also a role dimension to this situation, since it can be unclear whether the colleague in question will be interpreted as a professional or as a private or personal agent in these exchanges.

Tempo dilemmas gradually emerged as a useful and relevant category during the exchanges with informants to this study. Things happen very fast in social media, and part of the attraction is to participate in a pulsating activity where intuitions are at play. The distinction that Kahneman (2013) has drawn between fast and impulsive (System 1) decision-making and slow and analytic (System 2) decision-making is relevant in this context. In the first chapter, it was used to explain the difference between moral intuition (System 1) and ethical analysis (System 2). Here, it can serve to highlight the fact that social media are designed for fast and impulsive decisions and exchanges, rather than slow and analytic ones. People who rely on the latter, when they are on Twitter or Facebook, are likely to feel that the discussion they wanted to contribute to has moved on and that their carefully crafted and more thoughtful expressions and phrases are no longer relevant.

Input from the executive students indicates that traditional leaders find the high tempo of social media particularly challenging, making them wary of entering into conversations in the digital domain. The leaders' dilemma is that, on the one hand, they are concerned about losing control on a communication platform characterized by rapid exchanges of words, where you may regret some of the messages you impulsively post, and on the other hand, they are afraid to miss out on business opportunities by staying away.

Some dilemmas in social media can have both a role and a tempo dimension in them, as in the example with the impulsive colleague, mentioned above. People can be quick and eager to join the fast timeline on Twitter and end up ignoring their roles in the organization. Here are some examples that came up in the teaching sessions:

- A CEO who uses the organization's account to express her personal views on the upbringing of children or on political matters-issues that lie far beyond her professional competence.

- A researcher who uses his professional account to raise harsh criticism about a particular aspect of the welfare system in his country. 
- An engineer who publicizes sexually charged comments from a conference he attends on behalf of the organization.

- A CFO who responds to reasonable criticism of one of the organization's products by going into a harsh and heated public dialogue with the sender.

Other people in the organization may be observers of this kind of rash behavior and can then encounter a choice between giving critical input to the agent and remaining silent. In some cases, this is a real dilemma, in that it is of high importance to stop the agent from putting himself or herself and the organization into further trouble; on the other hand, however, it may be a bad career move, since it may not be appreciated by the agent. In other cases, it is a false dilemma, as it is clearly appropriate to intervene and the personal cost of doing so is not all that high; it is, nevertheless, tempting to turn a blind eye to the situation to avoid personal trouble.

The high tempo of the exchanges on social media increases the likelihood of making mistakes. When things do go wrong, the person responsible for social media accounts faces dilemmas about how to cope with the situation. The opening example in the previous chapter can serve as an illustration of such an ex post tempo dilemma. The construction manager takes photos from a tunnel project in the mountains, and the communications person in the organization quickly posts them on Facebook. It provides a fresh, current and immediate report from the construction site, but one of the photos documents an HSE violation. Given the slower tempo in the publishing process, that mistake would most likely have been avoided in the days before social media. The decision-maker could have studied the photo more carefully before publication and might have spotted the violation - an employee not wearing a helmet. It was a social media mistake to publish and document the HSE mistake. In the aftermath of such events, the typical dilemma is to negotiate a balance between transparency and openness, on the one hand, and a concern for stakeholders like the employee, on the other.

Tempo dilemmas on social media also raise concerns over moral luck. Philosophers Nagel (1979) and Williams (1981) brought attention to how actual outcomes affect moral judgments of what people do. Research 
confirms that people tend to judge unlucky agents more harshly than lucky ones, even in the moral domain (Martin \& Cushman, 2016). The difference tends to disappear with a more careful and reflective consideration of the agent's contribution and lack of control (Kneer \& Machery, 2019). The difference between the immediate and intuitive judgments on the one hand and the slower and more analytic ones on the other follows the pattern of Kahneman's (2013) System 1 vs. System 2 line of thinking. When people spend time reflecting on the risk and the uncontrollable circumstances, they are less likely to judge the unlucky agent more harshly. That may be of little consolation to a professional who expects others to judge her impulsively and immediately, based on the actual outcomes of her behavior. Fear of bad moral luck can make employees wary of entering the high-tempo domain of social media.

A person responsible for running the social media accounts of an organization is exposed to moral luck, in the sense that actual outcomes of the high-tempo decisions he or she makes at work influence the moral judgments of those decisions, even though much of what happens is beyond that person's control. As in other areas of organizational life, people who operate in high-tempo and high-risk work environments deserve support and encouragement from superiors who understand the uncertain nature of the decision-making processes. An underlying feature of responses from the informants to this study is that they experience a lack of understanding from their leaders of the risks that naturally follow from operating in the high-tempo context of social media. It is not a viable option to drastically reduce the tempo of the decision-making to reduce the likelihood of making mistakes, since the existing tempo is essential to the function and thrill of social media.

\section{Integrity Dilemmas}

A third category to emerge from the material is that of integrity dilemmas. Presence on social media can put the integrity of individuals, groups and organizations under pressure, in that they can face situations where it is difficult to remain committed to their principles and values. They may experience moral dissonance (Kvalnes, 2019), a conflict between 
their moral convictions and what they are ordered or expected to do. One student gave the following example of how her organization found itself in a situation where doing the right thing, from the perspective of professional integrity, potentially jeopardized a commercial relation:

We are an applied research organization, offering clients research reports about their products. One of our clients started to use a production method that some of our researchers found would put the end users at risk, if they failed to take proper precautions. Our client did not see the need to inform the public or their customers about these facts. We needed to decide whether to, nevertheless, use social media and other sources to inform about the need to take precautions. In the process, we risked becoming unpopular with the client who produced it. In the end, we used all means possible to spread information to the public, and put the relation to a big client to the test.

In this case, professional integrity trumped concerns about losing out on further assignments from the client. In its application of social media, the organization gave priority to the value of food safety over potentially negative economic outcomes. They found a way of doing so that turned out to be acceptable to the client and so did not lead to a commercial loss. We can study even this process through the lens of moral luck. It was risky to prioritize their own principles over the wishes of the client, but the actual outcome somehow justifies that decision, even if factors beyond the decision-makers' control may have influenced how things turned out.

Integrity is central to how individuals, groups and organizations preserve unity over time (Cox, La Caze, \& Levine, 2018). A person or organization of integrity builds decision-making and behavior on a set of stable standards and principles. These are not open to negotiation. There can be tensions between different kinds of integrity, as between professional and personal integrity, where commitment to work-related standards can conflict with commitment to standards that are central to life outside of work. We can interpret the example above as a conflict between professional and public service-oriented integrity, on the one hand, and commercial integrity, on the other. A core component in the latter kind of integrity is to be of service to the clients and their needs. 
Integrity dilemmas can occur in a range of exchanges within the framework of social media. In classroom discussions, the executive students described situations where the ambition to increase the number of friends or followers (and thus reach out to potential clients or customers) one has on social media can make it tempting to:

- Like and share content that you actually find uninteresting, uninspiring and even questionable or wrong.

- Refrain from speaking up against content that you disagree with or find appalling.

Both of these responses depend on putting your own moral convictions and beliefs aside to become and remain popular with actual or potential friends and followers. To see growth in the number of followers or friends on social media, management in an organization may expect their employees to keep personal convictions and values in check, even when these are well-aligned with what the organization itself is supposed to stand for. It can be a matter of sacrificing both personal integrity and organizational integrity to become and remain popular in the eyes of potential clients.

Personal ambitions to remain popular and well-liked can also make it tempting to compromise individual values:

My organization promotes contemporary music, and we struggle to reach out to audiences in an effective manner. We are active on Facebook, and share information and sell tickets to events. From the music community, we are under constant pressure to share and like their events, both as an organization and individually. On my private Facebook and Twitter accounts I can choose which events to recommend, like, and share. Can I single out content that I think is good and worth spreading, and be more selective in what I help to promote? That is what I want to do, since it hurts to recommend trash. If I follow my values, I will become unpopular in many quarters, where my name and profile is well known.

It hurts to recommend trash, even if it may have other positive consequences. This decision-maker frequently faces situations where it can be 
profitable to downplay personal and organizational values for the sake of popularity. However, the gains may only be temporary and short term. Research on corporate identity and values indicates that keeping one's organizational integrity intact is good for long-term profitability. Commitment to a stable set of values can be instrumental to corporate flourishing (Chye Koh \& Boo, 2004; Collins \& Porras, 1996) and make employees less likely to leave the organization (Haque, Fernando, \& Caputi, 2019). Sacrificing organizational and professional integrity for popularity on social media is risky, but it can be what organizations expect from those who run their social media outlets.

Some dilemmas have a role dimension, as well as an integrity dimension to them. One student shared an example from her job as part of the editorial team of a lifestyle magazine. The owners of the magazine had recently decided to hire an advertising bureau to run their Twitter and Instagram accounts, to make the use of those platforms more professional. People from the bureau posed as journalists from the magazine and invited people to meet "us" at different destinations. The actual journalists were unhappy about this arrangement and argued that the users would be conned into thinking that they were actually meeting real representatives from the magazine. The owners created role confusion, and the journalists faced a test of their integrity. They had to decide whether they were willing to work for a magazine that hired externals to run their social media platforms in this manner.

The majority of executive students who reflected on this dilemma in the auditorium tended to sympathize with the journalists and agreed that it was an affront to their personal and professional integrity to accept that externals would run their social media accounts. However, when the author presented the same dilemma to a younger group of students (20-25 years of age), a different response pattern emerged. These students tended to find it unproblematic to hire a bureau to run the social media accounts for an organization and even claim to have readers meet "us" at events.

Integrity dilemmas occur on personal, group and organizational levels. Their common feature is that the decision-maker's values and principles are tested. Several of the informants to this study describe how their roles of running social media accounts on behalf of their organizations 
regularly put them in the middle of situations where they can defend and protect integrity on all three levels, or sacrifice it for economic or other gain. It thus seems important to prepare professionals who are assigned to such roles for these kinds of dilemmas.

\section{Speech Dilemmas}

What kinds of standpoints and views are acceptable to express on social media? This is the question behind a range of examples provided by the informants to this study. They have faced situations where one set of considerations supports the publication of an expression and another set of considerations goes against it. Speech dilemma was a category name proposed, tested and accepted for this kind of situation early in the study. A typical situation is that the organization receives harsh criticism on social media, based on a misrepresentation of facts:

I work in a bank in my hometown. After having financed the startup of a local company, we decided to say no to further loans to finance expansion plans. The company went bankrupt some months later, since it was not able to collect capital from other sources. The owner felt that our "no" came at a time where the company was about to turn a corner, while our decision was based on an evaluation of past events, communication, risk, market development, and so on. When the bankruptcy occurred, the owner used Facebook to attack the bank and employees and managers within it, hitting us with false information about the process. How were we supposed to respond? We could, of course, not use factual and sensitive information, and correct his version. One possibility was to give a general reply that our decisions are always based on an evaluation of the totality, and that our clients sometimes would disagree about interpretation of the facts, and so remind people that there are always at least two sides to a case. We decided to do nothing, and now see this experience as an example of how powerful Facebook can be, and how powerless you can be in responding to criticism expressed there.

In this situation, the bank apparently found itself in a false dilemma, since the alternative of using Facebook to actively respond to the false 
allegations was ethically and legally wrong. There was a scope of action for a more general response, which did not include the revelation of sensitive information, but the bank decided against it, since that response probably would have prolonged the time it spent in the public spotlight.

Other examples in the data follow a similar pattern to the one above. In one, a restaurant faces the choice between defending itself against false social media accusations from a bad-tempered customer and remaining calm. The problem with the latter response is that the digital traces of the criticism are likely to remain, turning up when potential customers search for information before they determine whether to come there for a meal. A nonresponse can be interpreted as acceptance of the allegations.

With traditional publication channels, it is up to the editors to decide what to publish. With social media, this decision level has disappeared, and the agents who consider the publication of personal messages and messages on behalf of organizations must account for ethical aspects. The absence of the traditional editorial processes prior to publishing means that questionable messages can be posted, reaching a wide audience. People can inflict pain on themselves and others, as in the following example:

A colleague is sharing very personal and sensitive information about her own mental health and how it affects her family life. I believe it worsens the situation for the children in the family. Her own view is that problems should be shared, and that openness is a good thing. Her texts are sometimes posted openly on Facebook, and sometimes within a group of Facebook friends. Some of her claims are also about conditions at work, and her frustrations with our organization. "This job is killing me" and "I don't have the energy to turn up at the office today" are examples of what she posts on Facebook.

Colleagues of this person face the task of finding adequate ways to respond. The situation is similar to one of the tempo dilemmas discussed earlier, the difference being that here, the questionable openness is not caused by impulsiveness and the high tempo of the medium; rather, it flows from a sense of freedom to express whatever one wants, without interference from anybody. 
Social media provide platforms for free speech and political activism (McCarthy, 2017; Shirky, 2011). They have also become platforms for trolling, hate speech, harassment, fake news and other kinds of misinformation (Bakir \& McStay, 2018; Craker \& March, 2016; Hannan, 2018; Lazer et al., 2018; Nicol, 2012; Pennycook \& Rand, 2019). Providers like Facebook and Twitter are expected to function as moderators, to maintain some ethical standards concerning the flow of information they allow. The general ethical tension is between promoting free speech, on the one hand, and being on guard against harmful expressions, on the other. Political exchanges on social media can sometimes include rude and hateful expressions. The importance of moderating the exchanges is underlined by research, documenting the contagiousness of trolling and harassment on social media. People who are normally well behaved tend to adopt harassing behavior if they are regularly exposed to that kind of behavior (Cheng, Danescu-Niculescu-Mizil, Leskovec, \& Bernstein, 2017). The handling of speech dilemmas and questions of what to publish can therefore have practical consequences.

Some speech dilemmas are also closely linked to role dilemmas, as when researchers get personally involved in political debate on matters they have knowledge about through their work:

I work with researchers who provide important input to political processes on a national level. Some of them participate in discussions on social media about issues related to their expertise. In a range of cases, their personal political views shine through. We are concerned about the researchers' freedom of speech, but when their political preferences become evident in public, it can negatively affect the trust in their independence and objectivity as researchers. We are planning to formulate guidelines for their activities in social media.

An initiative to establish guidelines or a code of conduct can be commendable, because it raises up to a principled level the issue of when and how it is acceptable for researchers and other practitioners to express their personal views on social media (Lipschultz, 2017). However, attempts to demarcate between acceptable and unacceptable expressions can be seen as an infringement on the researchers' autonomy. Detailed guidelines 
may also inadvertently lead to loophole ethics or the attitude that anything they are silent about is acceptable (Kvalnes, 2019).

When employees explore the limits of their freedom to express their views through social media, it may fall to their colleagues, rather than their leader, to address the issue with them. The following situation is representative of what the executive student informants in this study claim to face when a colleague behaves in a manner that the management finds unacceptable:

I am working for a public directorate. The minster has initiated dramatic changes in our procedures. One of my colleagues is very critical of these changes, based on his expertise and experience. He uses Twitter to express his criticism of the minister's initiative, and receives so much attention that even the non-digital management in the directorate gets to hear about it. Now they ask me, as a representative of the communications unit, to tell the colleague to stop using Twitter to express his critical views. How should I proceed?

Here, we have a situation where the management steps away from a testing set of circumstances and leaves the responsibility of taking action with the person who has the most social media competence. As such, it takes the form of a role dilemma, where the agent must decide whether to follow orders to do a manager's job. It seems that it is actually the management's responsibility to address the issue with the employee causing alarm with his social media use, but the task is instead pushed to the person most competent in the use of the technology. That person can also face an integrity dilemma, in that he or she may feel that following orders, in this case, requires a sacrifice of personal values and principles.

In this section, we have seen that a range of dilemmas on social media are connected to speech and expression, and where to draw the line regarding content that can hurt the sender or receiver of messages posted on social media. The examples show that speech dilemmas tend to overlap with dilemmas in the other categories. Depending on perspective, a dilemma situation may be described in terms of role, tempo, integrity and speech. This tendency to overlap is addressed toward the end of the chapter. 


\section{Competence Dilemmas}

The first and second rounds of memos and discussions with the informants in this study gave rise to four tentative categories of dilemmas. Students and researchers were able to agree that the examples fit into the categories of role dilemmas, tempo dilemmas, integrity dilemmas and speech dilemmas. However, another set of examples did not fit properly into any of these categories. Experienced users of social media explained how they had built up professionalism and competence, and tended to meet internal stakeholders (leaders/managers, colleagues) and external stakeholders (customers, clients, competitors, authorities) who, by contrast, were novices. They raised the following ethical question: To what extent is it acceptable to exploit the competence gap to one's own benefit?

Internally, a competence dilemma can occur when social media experts interact with colleagues and leaders who have limited experience with the workings of those communication channels. It puts the experts in a powerful position. The competence gap makes it possible for them to influence internal processes in ways that are invisible to others. Both of the candidates for an internal promotion may need some guidance in social media usage, to increase their chances of getting the job. The social media expert can observe that this is the case and decide whether to offer guidance. Informants to this study have described how withholding or offering social media support can be an effective way of influencing the progress of a colleague's career or the direction of a particular internal project.

Competence dilemmas also arise in the context of external relations. One informant described a situation where she was able to get a profitable assignment for her organization by introducing clients to social media platforms that they may have lacked the competence to master:

We have clients in professions that do not have a tradition for written communication, like industry workers, craftsmen, and health care personnel. They can potentially make good use of Facebook to reach the strategic goals with their small companies, but sense that they do not master the language well enough to use it. They are afraid of being arrested by the "language police" for misspellings and grammatical mistakes. Many of 
their clients are well educated, and more fluent in the written language, and if they experience lack of language mastery from the supplier, it may reduce the trust level. What should we advise our clients to do?

The best advice to these "illiterate" clients may be to find other platforms for communicating with the outside world. From the consultant's own perspective, however, it is more profitable to secure an assignment in which she can guide the clients into the social media world. A third option may be to be open about the risks of exposing one's lack of language mastery and honest about the efforts it will take to, nevertheless, make good use of Facebook, Twitter or other social media platforms. That option puts the clients in a position to make an informed decision about the way forward.

The category of competence dilemmas can account for situations that follow the pattern of the situation described above. They occur in provider-client relationships, where the provider can exploit a competence gap in relation to the client. This can be done by (1) offering social media services that the client has little or no use for and (2) pricing the services higher than their actual market value. The professional may be an expert on social media use and sell services that the client lacks the competence to evaluate, and the imbalance introduces the possible misuse of client trust. On this description, competence dilemmas belong under the heading of false dilemmas. They are examples of conflict-of-interest situations, where it is ethically appropriate to prioritize client interest over selfinterest, but economically tempting to do otherwise, particularly since the client lacks competence to realize that it is happening. As such, they are at the core of professional ethics (Nanda, 2003).

The informants to this study have been invited to share dilemmas connected to their roles as being responsible for social media accounts in the organizations. In these initial roles, they are not engaged in a providerclient relationship, and so the issue of competence dilemmas seems to be irrelevant. However, many of the informants have experience in taking on the additional role of advising clients about social media use, based on their competence in that area. As such, there are situations that professionals who assume such positions and roles should prepare for. 
Some informants have been skeptical of the competence dilemma category, because they can envisage situations where exploiting a competence gap in their own favor is perfectly natural. This is what normally occurs in a competitive business environment, both within a company and in relation to external competitors. If others are less competent, then that provides a reason to move forward and take advantage, rather than back off for ethical reasons. This misgiving points to a need to be precise in the description of the category. A competence dilemma in relation to external actors does not occur in connection with any kind of competence gap. It typically arises when there are clients or customers who assume that the professional will give priority to their interest, rather than self-interest. The social media expert is in a position to prioritize selfinterest without detection. These conflict-of-interest situations serve to test the professional's willingness to do the right thing (serve the client) and not give in to the temptation of giving priority to self-interest. As such, they are structurally similar to conflict-of-interest situations that can occur in any professional setting where a competence gap is present.

\section{A Spectrum of Dilemmas}

A discovery that emerged in the analysis of the student data was that one particular dilemma can include aspects from more than one of the categories outlined here and may, to some extent, belong in all five categories. The examples are not necessarily deep or complex. The following situation is one where the dimensions of role, tempo, integrity, speech and competence all are present:

One of my clients wants to give a finder's fee to people who would tip her about potential employees for a particular project. She wants me to help her share and spread the information in social media, through our Facebook, Twitter, and LinkedIn accounts. However, we also have clients who are in competition with her company, so am reluctant to do so. If I decline, it will hurt our relation to the client, but the alternative will most likely provoke other clients. What should I do? 
The agent here is in a dual role, as the supplier of one particular client who expects help, but also as a supplier for other clients. The situation demands a quick response and is one where there is little opportunity for slow and careful deliberation. It puts the supplier's integrity to the test, as there appears to be a conflict between what he or she thinks is the right thing to do (decline the request) and what it is tempting to do (honor the request). The speech dimension is also present, in that the agent must consider what it is acceptable for him or her to say, while the agent's competence in the use of social media is also in play.

Another example can further illustrate how several dilemma categories can be relevant to one situation:

Both Amnesty International and Greenpeace have international campaigns against my organization, with special emphasis on operations outside our own country. I think the campaigns are spreading misinformation about my employer, and personally wish to correct them. However, I work in the communications unit in my organization, and anything I express in social media can be interpreted as the organization's response to the allegations in the campaigns.

This agent faces a role dilemma, in that any personal expressions can be interpreted as being made on behalf of the organization. The high tempo of the exchanges on social media leaves an opening for impulsive responses that may not be beneficial for the agent or the organization. Integrity is at stake, in that the agent may have strong convictions that favor speaking up to confront misinformation and, at the same time, realize that there is a professional cost to doing so. Personal integrity may thus dictate a different approach to that favored by professional integrity. There is clearly a speech dimension to the dilemma, in that there are ethical costs attached to speaking up as well as to remaining silent. A competence aspect is that the agent is a knowledgeable person when it comes to the workings of social media, and therefore knows how the assumed misinformation can spread and become accepted as reliable and factual, and is also familiar with ways to counter that development.

It is not surprising that ethical dilemmas in the sphere of social media use in organizations can have aspects that fit with more than one and 
even with all five of the dilemma categories outlined in this chapter. The realities under scrutiny are multifaceted and can have overlapping features that are all ethically relevant.

A theoretical implication is that the proposed concepts and characterizations of dilemmas must reflect their ambiguity and richness. Instead of presenting the five categories as a list, it can be even more useful to place them in a model that acknowledges the possibility of more than one adequate description.

The question to ask, regarding one particular dilemma, may be to what extent it belongs under one categorization or under more than one. A dilemma may primarily be a role dilemma but also have some features that make it into an integrity dilemma or a tempo dilemma. Another dilemma may, most strikingly, be a speech dilemma but, in addition, belong under the heading of a competence dilemma. The model can also serve as a tool to express disagreement about the ethical core of a particular dilemma and thereby bring misunderstanding to the surface. People who apparently disagree about a course of action in a dilemma may actually do so because they have adopted different interpretations and categorizations of the situation at hand. It is well known that the framing of dilemmas can affect decision-making and choices (Cubitt, Drouvelis, \& Gächter, 2011; Fleishman, 1988; Fosgaard, Hansen, \& Wengström, 2019), and the current model can help bring framing differences to the surface.

The category model articulated above can serve as a starting point for moral reasoning about activities in social media and may turn out to need further elaboration. There may be ethical challenges for organizational users of social media that the framework does not capture adequately. Each of the five categories may have a potential for subcategories, to make the conceptualization more fine-tuned to the practitioners' experienced realities. For now, the model can serve as a tentative tool to zoom in on questions about ethically right and wrong, permissible, obligatory and forbidden actions in the use of social media in organizational settings, to assist practitioners in becoming aware of and handling ethical dilemmas at work.

It should also be clear that the overall categorization is not unique to social media. Clearly, there can be role dilemmas, tempo dilemmas, 
integrity dilemmas, speech dilemmas and competence dilemmas in organizational contexts that are unrelated to social media. The ambition here has not been to come up with dilemma categories that are present solely in relation to social media use in organizations. The descriptions in Fig. 2.1 connect the category labels more specifically to social media, but the general labels can be applied more widely in organizations.

This chapter has presented five categories of ethical dilemmas for professionals who run the social media accounts for organizations. The categorization builds on input from executive students at a European business school, all of whom work on digital transformation processes in their organizations and, more specifically, have a hand in running the social media platforms for the employers. The five categories, consisting of role dilemmas, tempo dilemmas, integrity dilemmas, speech dilemmas and competence dilemmas, emerged from a close reading of input from around 250 students. One and the same dilemma may have elements that place it in more than one of the categories. For practitioners, the categorization can assist them in reflecting systematically on the kinds of situations they may encounter at work. The next chapter proposes cognitive tools for going a step further, enabling the practitioners to analyze

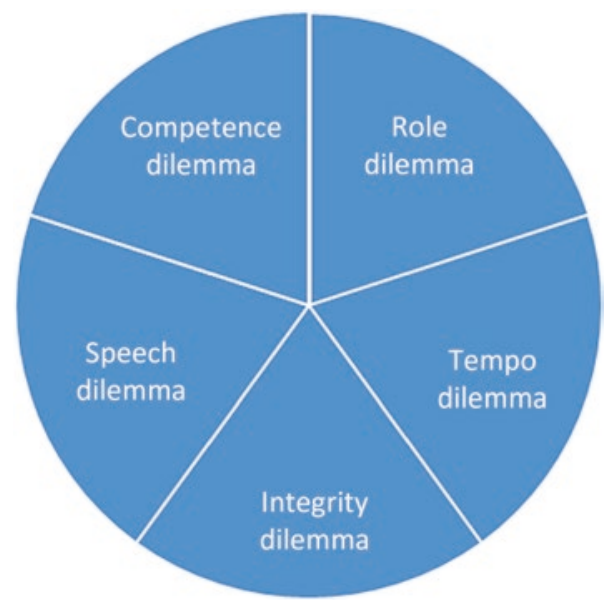

Fig. 2.1 Spectrum of dilemmas 
the dilemma at hand and reach a conclusion regarding the appropriate course of action.

\section{References}

Bakir, V., \& McStay, A. (2018). Fake news and the economy of emotions: Problems, causes, solutions. Digital Journalism, 6(2), 154-175.

Cheng, J., Danescu-Niculescu-Mizil, C., Leskovec, J., \& Bernstein, M. (2017). Anyone can become a troll. American Scientist, 105(3), 152.

Chye Koh, H., \& Boo, E. F. H. (2004). Organisational ethics and employee satisfaction and commitment. Management Decision, 42(5), 677-693.

Collins, J. C., \& Porras, J. I. (1996). Building your company's vision. Harvard Business Review, 74(5), 65.

Cox, D., La Caze, M., \& Levine, M. P. (2018). Integrity and the fragile self. London: Routledge.

Craker, N., \& March, E. (2016). The dark side of Facebook ${ }^{\oplus}$ T The dark tetrad, negative social potency, and trolling behaviours. Personality and Individual Differences, 102, 79-84.

Cubitt, R. P., Drouvelis, M., \& Gächter, S. (2011). Framing and free riding: Emotional responses and punishment in social dilemma games. Experimental Economics, 14(2), 254-272.

Fleishman, J. A. (1988). The effects of decision framing and others' behavior on cooperation in a social dilemma. Journal of Conflict Resolution, 32(1), 162-180.

Fosgaard, T. R., Hansen, L. G., \& Wengström, E. (2019). Cooperation, framing, and political attitudes. Journal of Economic Behavior \& Organization, $158,416-427$.

Hannan, J. (2018). Trolling ourselves to death? Social media and post-truth politics. European Journal of Communication, 33(2), 214-226.

Haque, A., Fernando, M., \& Caputi, P. (2019). The relationship between responsible leadership and organisational commitment and the mediating effect of employee turnover intentions: An empirical study with Australian employees. Journal of Business Ethics, 156(3), 759-774.

Kahneman, D. (2013). Thinking, fast and slow. New York: Farrar, Straus and Giroux.

Kneer, M., \& Machery, E. (2019). No luck for moral luck. Cognition, 182, 331-348. 
Kvalnes, Ø. (2019). Moral reasoning at work: Rethinking ethics in organizations (2nd ed.). London: Palgrave Macmillan.

Lazer, D. M., Baum, M. A., Benkler, Y., Berinsky, A. J., Greenhill, K. M., Menczer, F., ... Rothschild, D. (2018). The science of fake news. Science, 359(6380), 1094-1096.

Leonardi, P. M. (2017). The social media revolution: Sharing and learning in the age of leaky knowledge. Information and Organization, 27(1), 47-59.

Lipschultz, J. H. (2017). Social media communication: Concepts, practices, data, law and ethics. New York: Routledge.

Martin, J. W., \& Cushman, F. (2016). The adaptive logic of moral luck. In The Blackwell companion to experimental philosophy. Hoboken, NJ: Wiley-Blackwell.

McCarthy, C. (2017). Balance social media concerns with free speech rights. College Athletics and the Law, 14(5), 1-5.

Nagel, T. (1979). Moral luck. In Mortal questions. Cambridge: Cambridge University Press.

Nanda, A. (2003). The essence of professionalism: Managing conflict of interest: Division of research. Harvard Business School Background Note 903-120.

Nicol, S. (2012). Cyber-bullying and trolling. Youth Studies Australia, 31(4), 3.

Pennycook, G., \& Rand, D. G. (2019). Lazy, not biased: Susceptibility to partisan fake news is better explained by lack of reasoning than by motivated reasoning. Cognition, 188, 39-50.

Shirky, C. (2011). The political power of social media: Technology, the public sphere, and political change. Foreign Affairs, 90(1), 28-41.

Williams, B. (1981). Moral luck: Philosophical papers 1973-1980. Cambridge: Cambridge University Press. 
Open Access This chapter is licensed under the terms of the Creative Commons Attribution 4.0 International License (http://creativecommons.org/licenses/ by/4.0/), which permits use, sharing, adaptation, distribution and reproduction in any medium or format, as long as you give appropriate credit to the original author(s) and the source, provide a link to the Creative Commons licence and indicate if changes were made.

The images or other third party material in this chapter are included in the chapter's Creative Commons licence, unless indicated otherwise in a credit line to the material. If material is not included in the chapter's Creative Commons licence and your intended use is not permitted by statutory regulation or exceeds the permitted use, you will need to obtain permission directly from the copyright holder.

(c) (i) 